\title{
The study of heavy metals leaching from waste foundry sands using a one-step extraction
}

\author{
Marta Bożym ${ }^{1, *}$ \\ ${ }^{1}$ Opole University of Technology, Faculty of Mechanical Engineering, 76 Prószkowska Street, 45-758 Opole, Poland
}

\begin{abstract}
There are a number of leaching test which are used to evaluate the effect of foundry waste disposal on the environment (TCLP, SPLP, ASTM at al.). Because the spent foundry sand are usually deposited at the ground level and they have a similar structure to the soil, survey mobility of metals using the same methods seems appropriate. One-step extraction allows for the evaluation of the mobility and bioavailability of metals in soil and waste. Waste foundry sands have been successfully used as a component in manufactured soils in U.S., but concern over metal contamination must be eliminated before considering this direction of use. The study evaluated the leaching of heavy metals $(\mathrm{Cd}, \mathrm{Pb}, \mathrm{Cu}, \mathrm{Zn}, \mathrm{Cr}$, Ni) from deposited waste foundry sands. The overall, as well as heavy metals were extracted by different type of extractants: $\mathrm{H}_{2} \mathrm{O}, \mathrm{CH}_{3} \mathrm{COOH}, \mathrm{HCl}$, EDTA, $\mathrm{MgCl}_{2}$ and $\mathrm{NaCOOH}$. These extractants are most commonly used to study the mobility and bioavailability of metals in soil and waste. In the present study applicable standards and methodology described in the literature in analysis were used. The results allowed to evaluate the bioavailability of metals leached from those wastes.
\end{abstract}

\section{Introduction}

After Poland's accession into the European Union, it took an obligation upon itself to pass and implement the environmental laws of the EU. With regard to industrial activity, Council Directive 96/61/EC was passed on industrial emissions (Integrated Pollution Prevention and Control - IPPC) [1,2]. One of the provisions of this directive stipulates the necessity of limiting the volume of waste production in industry. The implementation of this directive in foundries needs to involve waste regeneration to the greatest extent that is possible. The list of the solid waste from foundries includes molding and core masses, dusts and slimes from gas treatment activities, smelter slags, waste refractory materials and spent grinding materials.

The greatest ratio of the waste is formed by foundry sands, which are commonly further reused after their regeneration $[3,4]$. The waste foundry and core sands can be successfully applied in other industrial branches as well. Among others, they can be used in road building and production of asphalt, as well as in building engineering in the production of concrete mortars. In addition, they are applied in the production of ceramic produce in the place of sand. An interesting solution which is applied in the US is associated with the application of waste foundry sands in gardening $[5,6]$. Another solution is postulated by the Finns. Waste foundry sands are applied in composting stations there. However, regardless of the actual application, all waste needs to be tested with regard to leachability parameters prior to their reuse. The assessment of heavy metal leaching usually applies immersion in water extracts. In addition, an adequate assessment of the impact of the waste on the environment can apply dedicated extraction methods, such as ASTM, TCLP, SPLP along with others [7-11]. For the case when molding sands are applied in agriculture and gardening, it is recommended to conduct a study of the soil as well. This is done with the purpose of determining the mobility of heavy metals and potential toxic impact of waste on plant and soil organisms [12-14]. In 2007, US EPA confirmed that benefits resulting from the application of waste foundry sands in agriculture and gardening as well as in geotechnical applications. The advantages of this application include the protection of natural resources as a result of reducing the demand for the raw materials, saving of energy and reduction of greenhouse gas emissions as a result of the reduction of mining activities and decrease of storage costs. Lindsay and Logan [15] state that the application of waste foundry sands in agriculture needs to be supported by research, which has to confirm their applicability for the designated purpose and the ones which provide means of monitoring their impact on the environment. Up to this date, there are no long-term studies into long-standing use of waste foundry sands in agriculture and into the ecological outcomes of this application. Dayton et al. [16] explain that the purpose of assessing the impact of the waste foundry sands in agriculture need to involve studies into leaching of the pollutants and its impact on the plants. It is often emphasized that waste foundry sands can be applied in the environmental after the materials comprise natural binders, e.g. bentonite or materials following

Corresponding author: m.bozym@po.opole.pl 
their thermal regeneration, which involves a thermal decomposition of the organic binders.

The assessment of heavy metal mobility in environmental samples applied extraction techniques. Such means of analysis provide information on the ratio of forms with various bioavailability, which is later converted into the total content. This proves useful for instance in the conditions when assessment of metal ion migration from soil into plant is undertaken. The assessment of bioavailability of microelements in solid samples applies leaching methods by application of various extracting agents. The mobility and bioavailability of metals is relative to their physical form and type of binding with the matrix. There are various methods applied for this purpose. The methods involving chemical metal leaching can be classified into singleand multi-stage. The advantage of the single-stage methods are associated with their short duration and the capability to obtain the results quickly. In contrast, the multi-stage (speciation) methods apply techniques of separation of the individual metals form in a given matrix through a number of stages. The advantage of these methods involves a precise manner of assessing the chemical forms of metals and the ability to easily predict their bioavailability. The drawbacks are connected with the time-consuming process and the necessity to use a number of extraction agents.

Heavy metals and other elements of the environment are bound to the main fractions in soil. In a paper dating back from 1979, Tessier et al. [17] identified 5 fractions. Fraction 1 is formed by metals bound in an active form (soluble fraction) and exchangeably bound metals (exchangeable fraction). This is a fraction comprising metals with the greatest mobility and bioavailability. Fraction 2 is formed by metals bound to carbonates, phosphates and sulfates (carbonate fraction). Metals in this fraction are potentially mobile and bioavailable in certain environmental conditions, usually in the conditions accompanied by a low $\mathrm{pH}$. Fraction 3 is formed by metals bound to $\mathrm{Fe}$ and Mn oxides. These structures are unstable in the condition marked by a low oxidation and reduction potential (Eh), and the reduction of the $\mathrm{Mn}$ and $\mathrm{Fe}$ oxides under anaerobic conditions and their further decomposition can lead to the adsorption of heavy metals. Fraction 4 is formed by metals bound to organic matter and sulfides (oxidizable fraction). The metals bound to this fraction can be released as a consequence of mineralization in the conditions of an extremely oxidized environment. The last one, i.e. residual fraction is made up by metals bound to the mineral matrix, and this fraction is virtually unavailable for plants. The literature of the area contains a number of further modifications of the Tessier's method [17]. Due to a variety of procedures involving metal extraction, there is an issue associated with their harmonization and standardization. As a consequence, a study was initiated in 1987 within the framework of the EC Standards, Measurement and Testing Program (SM\&T, formerly $\mathrm{BCR}$ ). As a result, standardized procedures of metal separation techniques in soils and environmental were introduced and a three-stage fractioning method was developed [18]. However, several European countries apply more simplified techniques used for assessing bioavailability of metals in soils, as they involve just a single stage. For instance, $1 \mathrm{M} \mathrm{HCl}$ solution is applied for the purpose in assessment of bioavailability in the Chemical and Agricultural Stations in Poland [19-21]. In other countries, this purpose is served by the use of salt solutions with the concentration that is similar to the one in soils. Other solutions include the use of $0.01 \mathrm{M} \mathrm{CaCl}_{2}$ in the Netherlands [22], 0.1 $\mathrm{M} \mathrm{NaNO}_{3}$ in Switzerland $[23,24]$, and $1 \mathrm{M} \mathrm{NH} \mathrm{NO}_{3}$ in Germany [25]. The legal regulations in France provide for the use of the DTPA (NFX31-121) and $1 \mathrm{M} \mathrm{NH} \mathrm{NH}_{3} \mathrm{COO}$ buffered solutions [26].

The aim of this study was a research involving waste foundry sands in terms of the leaching of heavy metals from them. The research was undertaken by application of selected extraction agents, which define the mobility and bioavailability of metals present in the waste.

\section{Materials \& Methods}

The research reported here applied waste foundry sands that were derived from waste deposited in an industrial waste landfill located in one of Polish foundries. The waste was extracted from various spots in the landfill in order to test waste stored across various periods in time: 1) mixed waste landfilled in the 1980s utilized in the production of road-building aggregates, 2) waste foundry and core sands landfilled in the 1990s that were not mixed with other types of waste, 3) and 4) mixed molding waste put to landfill throughout 2012 throughout various seasons, 5) mixed foundry waste landfill in the 1980s and remaining there in an unchanged form. The samples were collected from several spots located in the landfill. A laboratory sample with the weight of around $1 \mathrm{~kg}$ was separated by the quartering technique. After they were taken to a laboratory, the samples were dried, homogenized, ground in a mortar and passed through a sieve. The samples were subjected to extraction by application of selected extraction agents and the level of heavy metal content was determined in them by application of Flame Atomic Absorption Spectrometry (FAAS) by means of Thermo M6 SOLAAR spectrometer. The determination of the total metal content in the waste samples, they were mineralized with aqua regia by application of the Milestone Start D Microwave digestion system. The following extraction agents were applied for the analysis:

- Water $\left(\mathrm{H}_{2} \mathrm{O}\right)$ in accordance with the procedure provided in the Polish PN-EN 12457-4 standard [27], metals in the forms with greatest mobility are subjected to leaching by this method;

- $0.11 \mathrm{M} \mathrm{CH}_{3} \mathrm{COOH}(0.11 \mathrm{M} \mathrm{Ac})$ in accordance with the procedure provided in SM\&T [18]: $40 \mathrm{~mL}$ of a 0.11 $\mathrm{mol} / \mathrm{LCH} 3 \mathrm{COOH}$ solution was added to $1 \mathrm{~g}$ of dry material and all was shaken for $16 \mathrm{~h}$ in room temp. Tis method is applied for leaching of metals in the ion-exchangeable and carbonate forms. Acetic acid is a non-specific acid and can be applied for leaching metals bound to silicates and carbonates; 
- $0.1 \mathrm{M} \mathrm{HCl}[26,28]$, this method is used for leaching metals bound to the majority of mobile fractions, this also includes the ability of leaching selective sulfates and metal silicates to a certain extent. Methodology: dry material was extracted with $0.1 \mathrm{M} \mathrm{HCl}$ with $1: 10$ ratio and shacked $1 \mathrm{hr}$ in room temp.;

- $1 \mathrm{M} \mathrm{MgCl}_{2}$ in accordance with Tessier et al. [17], it is used for leaching ion-exchangeable fractions, however, it does not impact metals bound to alumino-silicates and hydroxides due to the neutral $\mathrm{pH}$ of the salts. Methodology: $1 \mathrm{~g}$ of material was extracted at room temperature for $1 \mathrm{hr}$ with $8 \mathrm{ml}$ of $\mathrm{MgCl} 2$ solution at $\mathrm{pH} 7$;

- $1 \mathrm{M} \mathrm{NaCH}_{3} \mathrm{COO}(\mathrm{NaAc})$ with the $\mathrm{pH}$ value of 5.0 in accordance with Tessier et al. [17], it is used for leaching metals bound to ion-exchangeable and carbonate fraction, i.e. mobile fractions. Methodology: 1g of material was extracted with $8 \mathrm{ml}$ of $1 \mathrm{M}$ sodium acetate at $\mathrm{pH} 5$ for $5 \mathrm{hrs}$ at room temperature;

- $0.05 \mathrm{M} \mathrm{Na} \mathrm{Na}_{2}$ EDTA (EDTA) in accordance with McGrath et al. [29]. Methodology: $5 \mathrm{~g}$ of material was extracted with $50 \mathrm{ml}$ of $0.05 \mathrm{M}$ Na2EDTA solution ( $\mathrm{pH} 7$ ) for $1 \mathrm{hr}$. This technique is applied for leaching carbonate and organic fractions of metals. It indicates the occurrence of metals in the forms that are best assimilated by plants. For the case of this extraction agent, there is a possibility of isolating metals from organic complexes and insoluble organo-metallic compounds [30].

All the tests that are reported here were repeated at least three times. The purpose of the confirmation of the analytical correctness applied the conducted analysis of certified material „Metals in soil” CRM028-050 Tusnovics.

\section{Results and discussion}

No considerable differences between samples of waste (No. 1-5) could be observed with regard to heavy metal leaching. Therefore the results were mediated and reported as the mean of the five analyzed samples. The examined waste was characterized by a various heavy metal content. Fig. 1 contains the cumulative information regarding heavy metal concentrations in the examined samples.

The highest concentration of heavy metals in sample no. 5 was analyzed, i.e. sample collected from the waste put to landfill in 1980s and remaining there in an unchanged form, as it was not processed further. It was established that chromium has the highest concentration in this type of waste $\left(264 \mathrm{mg} \mathrm{kg}^{-1}\right)$. A similar level of chromium concentration was recorded in sample no. 3, which is formed by the waste landfilled in 2012. The high concentration of chromium in comparison to other metals was found by the special characteristics of the production process. The plant from which the waste was derived manufactures cast iron and cast steel components. In this case, the high concentration of chromium in comparison to other metals was affected by the special characteristics of the production process.

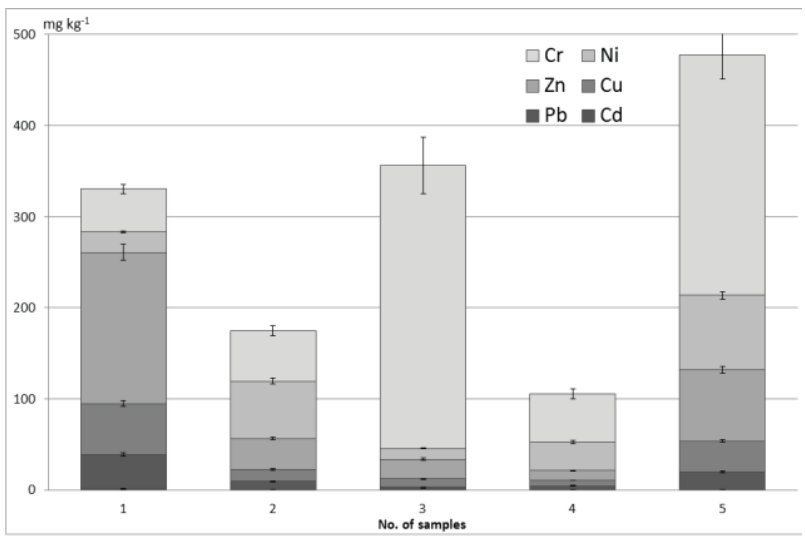

Fig. 1. Total heavy metals concentration in foundry waste samples.

The plant from which the waste was derived manufactures cast iron and cast steel components. Such production often applies additions of other metals, including nickel, zinc and other, which provides the end production with relevant product parameters. Hence, among all metals, the zinc and nickel concentration was increased. The examined waste demonstrated a very small cadmium concentration $\left(0.5-1 \mathrm{mg} \mathrm{kg}^{-1}\right)$. The lowest metal concentration was established in sample no. 4, which is formed by waste landfilled in 2012 and is derived from the most recent production. The differences between the metal concentrations in samples originating from 2012 are noteworthy, in the consideration of the fact that they were put to landfill at different times. This could also be attributable to special characteristics of the production process. This also demonstrates that the composition of the foundry waste varies depending on time and type of production. The composition of from waste foundries is affected by the use of waste foundry sands, ashes, slag, refinery materials and others. Besides, the composition of the cast iron and type of binders used in the molding sands also impacts the waste composition. A common hazard is associated with waste foundry sands containing organic binders, which can release hazardous compounds including phenol, formaldehyde, PAHs and others [2-4].

The degree of pollutant leaching impacts the harmful effect of landfilled waste. This aspect is taken into consideration during the designed further application of this waste. Table 1 contains the results of heavy metal leaching from the examined waste by application of six extraction agents. The metal leaching for a each fraction was converted into the percentage ratio in relation the total content.

The study demonstrates that the leaching in the environment when $\mathrm{H}_{2} \mathrm{O}$ was used was marginal. This type of analysis is performed with the purpose of determining the impact of the landfilled waste on the environment [31]. As a result of the fact that the recorded results of metal leaching from the waste was low, the waste can be classified as neutral. The extraction by use of deionized water usually results in leaching of metal ions and ion complexes of the soluble organic matter. Such metals are actively bound (soluble 
fraction). It contains metal forms with the highest mobility and availability [30,32].

The extraction by application of neutral salts of organic acids and strong alkalis leads to the leaching of the fractions with the highest mobility, as they can be released from waste during storage, whereas metals in chemically bound forms are not susceptible to leaching [30]. This fraction comprises metals with weak sorption characteristics, principally the ones, which are blocked on the surface of mineral particle by relatively weak electrostatic forces and the ones that can be released during ion exchange. In the examined waste, the ratio of metals included in this fraction is relatively small (1$12 \%$ ) (Table 1). The greatest leaching capability was noted for the case of zinc. This result is also gained with regard to soils. Zinc occurs predominantly in the mobile form in soils.

Table 1. The percentage of elution compared to total concentration of heavy metals calculated for each sample and total content of heavy metal.

\begin{tabular}{|c|c|c|c|c|c|c|}
\hline \multirow{2}{*}{ solution } & $\mathrm{Cd}$ & $\mathrm{Pb}$ & $\mathrm{Cu}$ & $\mathrm{Zn}$ & $\mathrm{Ni}$ & $\mathrm{Cr}$ \\
\hline & \multicolumn{6}{|c|}{$\%$} \\
\hline $\begin{array}{c}\mathrm{H}_{2} \mathrm{O} \\
\text { min-max } \\
\text { average } \\
\text { SD }\end{array}$ & $<\mathrm{LOQ}$ & $<\mathrm{LOQ}$ & $<\mathrm{LOQ}$ & $<\mathrm{LOQ}$ & $<\mathrm{LOQ}$ & $<\mathrm{LOQ}$ \\
\hline Ac & & & & & & \\
\hline $\min -\max$ & $9-26$ & $0-11$ & $8-13$ & $15-22$ & $2-6$ & $1-3$ \\
\hline average & 19 & 4 & 10 & 18 & 3 & 2 \\
\hline SD & 7 & 4 & 3 & 3 & 2 & 1 \\
\hline $\mathrm{HCl}$ & & & & & & \\
\hline $\min -\max$ & $27-37$ & $0-12$ & $8-15$ & $17-23$ & $4-7$ & $2-5$ \\
\hline average & 32 & 6 & 12 & 20 & 6 & 3 \\
\hline SD & 4 & 5 & 2 & 3 & 1 & 1 \\
\hline$\underset{\mathrm{MgCl}}{\mathrm{Mg}_{2}}$ & $5-12$ & $0-8$ & $2-8$ & 10-15 & $1-4$ & $0-1$ \\
\hline average & 9 & 3 & 6 & 12 & 2 & 1 \\
\hline SD & 3 & 3 & 3 & 2 & 1 & 1 \\
\hline $\mathrm{NaAc}$ & & & & & & \\
\hline $\min -\max$ & $24-30$ & $0-7$ & $4-9$ & $13-20$ & $1-4$ & $1-4$ \\
\hline average & 27 & 2 & 7 & 16 & 2 & 2 \\
\hline SD & 2 & 3 & 2 & 3 & 1 & 1 \\
\hline EDTA & & & & & & \\
\hline $\min -\max$ & $25-52$ & $0-14$ & $13-18$ & $20-25$ & $6-9$ & $2-5$ \\
\hline average & 42 & 10 & 15 & 23 & 7 & 3 \\
\hline SD & 11 & 6 & 2 & 2 & 1 & 1 \\
\hline \multicolumn{7}{|c|}{ Total content $\left[\mathrm{mg} \mathrm{kg}^{-1}\right]$} \\
\hline $\min$ & 0.553 & 2.4 & 6.1 & 10.6 & 11.6 & 47.1 \\
\hline $\max$ & 0.974 & 37.7 & 56.2 & 166 & 81.6 & 311 \\
\hline average & 0.777 & 14.3 & 23.7 & 62.1 & 41.9 & 146 \\
\hline SD & 0.189 & 14.6 & 21.3 & 63.5 & 29.3 & 130 \\
\hline
\end{tabular}

The extraction performed by application of $0.11 \mathrm{M}$ acetic acid [18] leads to leaching of the ionexchangeable metal fraction and carbonate fractions, as these forms are mobile. These forms can be released from waste. Acetic acid was leached the metals from the samples in a wide range. The greatest level of leaching was recorded with regard to cadmium (9-26\%) and zinc $(15-22 \%)$. The content of copper in the mobile fraction was equal to as little as $10 \%$ of the total metal content in the waste. Concurrently, the level of $\mathrm{Pb}, \mathrm{Ni}$ and $\mathrm{Cr}$ leaching was low(2-4\%).

According to Rao et al. [30] and Tessier et al. [17], the testing concerned with leaching of metal bound to carbonate fraction should apply acetic acid salts, of which sodium and ammonium acetate are most commonly used. The extractions applying NaAc, similar as in the case of $0.11 \mathrm{M} \mathrm{Ac}$, cadmium (24-30\%) and zinc $(13-20 \%)$ are predominantly used (Table 1). As for the level of leaching results of the remaining metals by the application of NaAc, it was found to be small (2-7\%). This is due to the fact that cadmium and zinc in the tested samples occur in the form bound to carbonates, and these forms are likely to be leached from landfills and in the conditions when they are applied in road construction and building engineering. Complexing agents (EDTA, DTPA) and inorganic acids form the strongest extraction agents [30,33,34]. Complexing reagents are capable of dissolving both the exchangeable fraction, as well as metals bound to the organic matter and hydroxides in soil. The metal content in these extract is significantly correlated with its ratio in the plants. Hence, the chelating factor is most commonly applied for the assessment of bioavailability of metals in soils $[18,30,33]$. EDTA forms a more powerful extraction agent than the remaining chelating substances, such as DTPA, HEDTA, NTA and EGTA. It was demonstrated that EDTA can lead to leaching greater quantities of metals compared to inorganic acids [28]. Acid extractions are applied with the purpose of leaching metals with stronger bonds, e.g. ones in the form of carbonates, Fe-Mn oxides and the ones that are bound to organic substances. Hydrochloric acid is capable of dissolving large quantities of microelements, which considerably exceed the nutritional demand of plants. As a result of this, its use is often criticised [35]. The procedures applied in Poland apply a method using $1 \mathrm{M}$ $\mathrm{HCl}$ for the assessment of the potential availability of metals in soils [21]. Therefore, it is recommended to substitute $1 \mathrm{M} \mathrm{HCl}$ solution with the one at a lower concentration: $0.1 \mathrm{M} \mathrm{HCl}[26,28]$. For the case of the tested waste, the recorded percentage ratios of metals after leaching by $\mathrm{HCl}$ and EDTA agents was the highest. The use of these extraction agents resulted in leaching the greatest quantities of cadmium and nickel, equal to: $\mathrm{Cd} 27-37 \%(\mathrm{HCl})$ and $25-52 \%$ (EDTA) vs. $\mathrm{Zn}$ $17-23 \%(\mathrm{HCl})$ and $20-25 \%$ (EDTA), respectively (Table 1). Concurrently, the ratio for the remaining metals was considerably lower. These studies suggest that the $0.05 \mathrm{M}$ $\mathrm{Na}_{2}$ EDTA proved to be the most effective extraction agent (in comparison to $\mathrm{HCl}$ ).

Throughout the assessment concerned with bioavailability of certain metals, some authors remark that salt solutions, such as $0.01 \mathrm{M} \mathrm{CaCl}, 0.1 \mathrm{M} \mathrm{NaNO}$ and $1.0 \mathrm{M} \mathrm{NH} \mathrm{NH}_{4} \mathrm{Ac}$, prove much more applicable in the determination of metal availability for plants in comparison to complexing extraction agents (EDTA, DTPA) and acids (0.1M HCl, $1 \mathrm{M} \mathrm{HCl})[28,36]$. The insights in the area suggest that the examined waste was characterized by a low percentage concentration of mobile and bioavailable fractions. Only for the case of cadmium and zinc, higher levels of leaching were 
registered in comparison to other metals. However, this fact does not disqualify their application in agriculture, since the registered cumulative cadmium concentration was very low, at a level, which normally occurs in soils. Aside from that, zinc has a very low toxicity and is considered to be indispensable for the plant growth. A greater hazard can be posed by organic compounds leached from landfilled waste. For these reason, the application of foundry waste is recommended only with regard to foundry sands not containing organic binders and the ones that are subjected to thermal regeneration prior to their use again.

\section{Conclusions}

1. Due to the low level of heavy metal leaching by application of water extracts, according to standard [26], the examined material formed by foundry sands was classified as a neutral waste. In general, the heavy metal content in water extracts measured in accordance with the PN-EN 12457-4 standard [26] was determined to be at a level below the limit of quantification.

2. The examined waste was characterized by various levels of heavy metal content. The greatest level was registered in sample no. 5, which involved the waste landfilled in the 1980s. The lowest concentration of pollutants was recorded in sample no. 4, which was landfilled in 2012. Besides, a considerable variability of the samples was observed with regard to the heavy metal content in them.

3. Chromium was the dominant metal in the examined waste. Slightly lower levels were registered with regard to zinc. This is attributable to the composition of the steel and iron in the produced casts. The waste had the lowest level of the pollution with cadmium.

4. It was established that cadmium forms the metal with the greatest mobility. However, due to the low cumulative content of this metal, the waste does not pose a serious hazard to the environment. The remaining metals occurred primarily in the immobile forms in the examined waste.

5. The highest ratio of heavy metal leaching was recorded as a result of application of $\mathrm{HCl}$ and EDTA eluents. These eluents can be used to demonstrate the quantities of mobile and potentially bioavailable forms. However, these metal forms can be leached from waste after a longer exposition period. The lowest leaching was observed by application of water, followed by $\mathrm{MgCl}_{2}$ salt. The use of the last eluent on this list results in the leaching of metals bound to exchangeable and carbonate fraction, which demonstrates the greatest mobility.

6. In general, the results indicate the low mobility and bioavailability of metals contained in the examined waste.

\section{References}

1. E. Bagińska, Arch. Foundry 2(3), 11-15 (2002)
2. M. Holtzer, Foundry J. Polish Foundryman's Assoc. 4, 314-321 (2004)

3. M. Holtzer, Arch. Foundry Eng. 7, 83-88 (2007)

4. M. Holtzer, Foundry J. Polish Foundryman's Assoc. 12, 950-955 (2004)

5. M. Bożym, I. Dąbrowska, Problems in environmental protection in the Opole Voivodeship waste and sewage, edited by K. Oszańca, Atmoterm, 24-41 (2012)

6. E. Smoluchowski, M. Zgut, Foundry Rev. Sci. Pract. 5, 31-33 (2005)

7. M. Bożym, K. Zalejska, Arch. Waste Manag. Environ. Prot. 16(3), 1-6 (2014)

8. A. Król, Environ. Prot. Eng. 38(4), 29-40 (2012)

9. A. Król, Chem. Industry 10, 971-973 (2007)

10. J. Kuterasińska, A. Król, Architecture Civil Eng. Environ. 3, 61-67 (2015)

11. M. Wzorek, Ecol. Chem. Eng. S, 19, 4, 617-627 (2012), doi: https://doi.org/10.2478/v10216-0110044-5

12. R.S. Dungan, J.S. Kim, H.Y. Weon, A.B. Leytem, Ann. Microbiol. 59(2), 239-246 (2009)

13. H. Zhang, L. Su, X. Li, J. Zuo, G. Liu, Y. Wang, Front. Environ. Sci. Eng. 8(1), 89-98 (2014)

14. K.C. Bastian, J.E. Alleman, Waste Manag. 18, $227-$ 234 (1998)

15. B.J. Lindsay, T.J. Logan, J. Resid. Sci. Techn. 2(1), 3-12 (2005)

16. E.A. Dayton, S.D. Whitacre, R.S. Dungan, N.T. Basta, Plant Soil 329, 27-33 (2010)

17. A. Tessier, P. G. Campbell, M. Bisson, 1979. Anal. Chem. 51(7), 844-851 (1979)

18. A.M. Ure, P. Quevauviller, H. Muntau, B. Griepink, Int. J. Env. Anal. Chem. 51, 135-151 (1993)

19. M. Bożym, A. Rajmund, Environ. Prot. Natural Res. 26(1), 1-6 (2015)

20. A. Rajmund, M. Bożym, Engin. Environ. Prot. 17(2), 231-241 (2014)

21. E. Ociepa, A. Ociepa-Kubicka, E. Okoniewska, J. Lach, Ann. Set Environ. Prot. 15, 1772-1786 (2013)

22. V.J.G. Houba, T.M. Lexmond, I. Novozamsky, J.J. van der Lee, Sci. Total Environ. 178(1-3), 21-28 (1996)

23. H. Hani, S. Gupta, Commission of the European Communities, Report 10361, 157-167 (1996)

24. VSBo, V.S. Verordnung über Schadstoffgehalt im Boden, Swiss ordinance on polluttants in soils. Nr. 814.12, 3000 Bren, Switzerland (1986)

25. DIN, Deutsches Institut fur Normung, Bodenbeschaffenheit. Extraktion von Spurenelemente mit Ammonium-nitratlosung. Vornorm DINV 19730, DIN (ed.) BodenChemische Bodenuntersuchungsverfahren, Berlin, Germany (1995)

26. E. Meers E., G. Du Laing, V. Unamuno, A. Ruttens, J. Vangronsveld, F.M.G. Tack, M.G. Verloo, Geoderma 141, 247-259 (2007)

27. PN-EN 12457-4:2006 - Characterization Of Waste Leaching - Compliance test for leaching of granular waste materials and sludges - Part 4: One stage batch test at a liquid to solid ratio of $10 \mathrm{I} / \mathrm{kg}$ for 
materials with particle size below $10 \mathrm{~mm}$ (without or with size reduction).

28. S. Chen, L. Sun, L. Chao, Q. Zhou, T. Sun, Bull. Environ. Contam. Toxicol. 82, 43-47 (2009).

29. S.P. McGrath, J. Cegarra, 1992. J. Soil Sci. 43, 313321

30. C. R.M. Rao, A. Sahuquillo, J.F. Lopez Sanchez, Water Air Soil Poll. 189, 291-333 (2008)

31. Regulation of the Minister of Economy of 16 July 2015r. on the acceptance of waste for landfill disposal (OJ 2015, item 1277)

32. V. Seguin, C. Gagnon, F. Courchesne, Plant Soil 260, 1-17 (2004)

33. M. Anju, D.K. Banerjee, Environ. Monit. Assess. 176, 67-85 (2011)

34. A. Bermond, I. Yousfi, J.P. Ghestem, Analyst 123,785-789 (1998).

35. S. Mercik, Agricultural chemistry Theoretical and practical basics, SGGW Warsaw, Poland (2004)

36. N.W. Menzies, M.J. Donn, P.M. Kopittke, Environ. Pollut. 145, 121-130 (2007) 